Морозов Игорь Владимирович

кандидат экономических наук, доцент, доцент кафедры «Экономика» Омского государственного университета путей сообщения

Исачкин Владимир Сергеевич

кандидат экономических наук, доцент кафедры «Экономика» Омского государственного университета путей сообщения

\section{ИСТОРИКО-ЭКОНОМИЧЕСКИЕ ПАРАЛЛЕЛИ СОВРЕМЕННОГО ЭТАПА РАЗВИТИЯ РОССИЙСКОГО ХОЗЯЙСТВА}

\section{Аннотация}

В статье анализируется связь современного отечественного хозяйства с историей развития экономики СССР, правопреемницей которого стала постсоветская Россия. В частности, изучаются структурные, технологические и функциональные аспекты условий и тенденций конкурентоспособного развития глобальных инновационных волн, относимых к началу формирования двух типов технологических систем хозяйства - индустрии 3.0 и индустрии 4.0. Особый упор делается на отрицательную в долгосрочном плане корреляцию оборонных расходов и увеличения ВВП, показывающую проблематичность длительного выполнения ими функции мультипликатора современного прогресса. Подобные проблемы увязываются не только с данными зарубежных ученых, но и с комплексом логических ошибок, возникающих в мерах политики государства по обеспечению конкурентоспособности хозяйства при создании инновационными волнами нового типа индустрии.

Ключевые слова:

конкурентоспособность, инновации, индустрия 3.0, индустрия 4.0, расходы на оборону, мультипликатор, экспорт сырья, экономика СССР.
Morozov Igor Vladimirovich

PhD in Economics, Associate Professor, Economics Department, Omsk State Transport University

Isachkin Vladimir Sergeevich

PhD in Economics, Associate Professor, Economics Department, Omsk State Transport University

\section{THE HISTORICAL AND ECONOMIC PARALLELS OF THE MODERN STAGE OF THE RUSSIAN ECONOMY DEVELOPMENT}

Summary:

The study analyzes the relationship between the modern Russian economy and the development history of the USSR economy succeeded by the post-Soviet Russia. In particular, the research examines the structural, technological, and functional aspects of the conditions for and trends in competitive development of global innovation waves related to the creation of two types of technological systems, i.e. industry 3.0 and industry 4.0. The emphasis is placed on the long-term negative correlation of defense spending with GDP growth demonstrating that they are unable to serve as a permanent multiplier of modern progress. Such problems are linked not only with the data of international scientists but also with a set of logical errors in the state policies on the competitiveness of the economy under the creation of a new type of industry by innovation waves.

Keywords: competitiveness, innovation, industry 3.0, industry 4.0, defense spending, multiplier, export of raw materials, the USSR economy.

Направленность взаимодействия экономической политики и экономического развития далеко не линейная. Главным образом это касается национальных хозяйств, которые пытаются конкурировать на мировом уровне самостоятельно или в блоковых союзах с другими странами, в особенности с учетом условий, накладываемых тенденциями глобализации или даже современной формальной деглобализации, более напоминающей векторные структурно-функциональные изменения ранее глобализованного мирового экономического пространства. Именно к такому типу хозяйств в полной мере можно отнести и экономику РФ, причем не только сейчас, но и исторически, с учетом глобальной конкуренции СССР путем организации собственной системы хозяйствования, правопреемницей которого стала Россия после его развала на рубеже 1991-1992 гг.

С одной стороны, экономической политикой современного Российского государства поставлена цель приоритетного развития цифровой экономики как достаточно четко выявившегося направления создания индустрии 4.0, выраженного в форме цифровизации хозяйственной среды функционирования. С другой - прогресс отечественного хозяйства имеет векторные пределы, корнями уходящие в ограничители предыдущего этапа и даже более раннего исторического периода развития, еще в рамках СССР, связанные с отставанием в становлении индустрии 3.0.

Более того, даже точки отсчета предшествующего типа индустрии и соответствующей ему научно-технической революции (далее - НTP) в XX в. играют немаловажную функциональную роль в понимании проблем будущего. В частности, согласно распространенной еще со времен СССР 
позиции отечественной экономической истории, НТР ведет отсчет с 1940-60-х гг., т. е. с предвоенной, военной и послевоенной конкуренции. Именно тогда успехи в освоении космоса вкупе с конкурентоспособным военно-промышленным комплексом (далее - ВПК, либо оборонно-промышленным комплексом, далее - ОПК) определили развитие СССР на уровне одной из двух конкурентных ведущих держав и, соответственно, экономик (и даже центров двух систем) мира. В современных исследованиях начало предшествующей НТР анализируется в связи с появляющейся ныне индустрией 4.0. Причем для этапа индустрии 3.0 зарубежные авторы указывают иное время старта - с 1960-х гг. [1, c. 16; 2, p. 13, fig. 2]. Аналогично другому взгляду на начальную точку индустрии 3.0 ученые обращают внимание на совершенно другие сфреры экономики (полупроводники, большие ЭВМ), по которым СССР не смог достичь в те времена конкурентного преимущества.

Цель нашего исследования состояла в том, чтобы определить, какие именно черты исторического прошлого должна учитывать современная экономическая политика при развитии новой индустрии 4.0 как конкурентоспособной на международном (региональном либо общемировом) уровне продукции. Тем более что пока важнейшим отличием индустрии 4.0 от индустрии 3.0 является в первую очередь ее постиндустриальная база возникновения, тогда как другие принципиальные различия в момент начала формирования новой технологической базы выделять исторически неправомерно: история показала наглядный пример образования промежуточных технологий мануфактурного периода, ключевое расхождение которых наблюдалось лишь в замене ручного труда машинным. Такие исторические уроки прошлого развития экономики можно учесть в структурном, функциональном и технологическом аспектах - тесно взаимосвязанных, но при этом относительно самостоятельных, способных формировать и потенциал совершенствования хозяйства, и его ограничители.

В частности, в структурном аспекте современное отечественное хозяйство есть результат длительной эволюции, причем имеющий исторически сформированные проблемы устойчивости в развитии ОПК, увеличения выпуска высокотехнологической продукции обрабатывающих секторов промышленности, противоречивого становления аграрного сектора и сферы услуг. Во-первых, ход переориентации российской экономики в 1990-х гг. показал тенденции углубления противоречий и кризисных явлений в данных областях, обратные целям их эффективного развития. Во-вторых, последовавшие в новом веке институциональная коррекция и начало активного государственного воздействия на указанные сегменты экономики привели по сути лишь к восстановлению их статуса, характерного для экономики СССР. Так, с середины 2010-х гг. возрождается идея приоритетности производств ОПК как мультиплицирующего локомотива индустриального и современного варианта постиндустриального наукоемкого развития [3].

Опыт исторического развития экономики СССР в послевоенное десятилетие, предшествовавший этапу зарождения в ней индустрии 3.0, показывает, что такой рычаг приведения хозяйства к устойчивому росту, хотя и ограниченный комплексом условий его эффективного влияния на экономику, вполне подходит для опоры. Например, помимо обеспечения национальной безопасности, мобилизация планового хозяйства на приоритетное развитие в нем ВПК содействовала превращению продукции данного комплекса в конкурентоспособные образцы мирового рынка с достаточно длительным и устойчивым спросом на них со стороны ряда субъектов мирового хозяйства. Тем самым СССР получил исторически обусловленную возможность воплощать указанные конкурентные преимущества в сфере военной техники и расширять свой экспортный потенциал. При этом продукция ВПК, как правило, высокотехнологична, а значит, спрос на нее стимулирует мультипликативное развитие науки, появление и внедрение через науку производственных инноваций.

Однако, во-первых, исследователи, аргументирующие опору на подобную мультипликативную роль оборонного комплекса, забывают о принципиальной разнице между ОПК и ВПК. Она состоит в том, что мультипликативный эффект развития ВПК имеет изначальный ограничитель во внешнеэкономическом спросе, где поставки, характеризующиеся накоплением с их помощью собственного оборонного потенциала другими странами, в значительной степени конечны ввиду скоротечности как прироста их потенциала, так и его дальнейшего поддержания. Немаловажны также выводы зарубежных авторов о статистически отрицательной связи в долгосрочном аспекте между ВВП и расходами на оборону [4, р. 16-17].

Во-вторых, упомянутые критерии, выдвигаемые в качестве источников и подтверждения зарождения во втором послевоенном десятилетии новой индустрии 3.0, отражают краткосрочность действия и ограниченность влияния мультипликативного эффекта роста ВПК при развитии соответствующих передовых отраслей индустрии 3.0. В частности, прогресс основных отраслей вне ВПК исторически имел совсем небольшое по длительности совпадение с ключевыми тенденциями и узкую сореру конкурентоспособности видов производств и деятельности. Получение с помощью ВПК конкурентных преимуществ СССР вне самого комплекса коснулось лишь сегментов космической инду- 
стрии с производной волной временных успехов в авиастроении. Тогда как остальные области, в особенности сфрормировавшие в будущем неразрешимые предкризисные проблемы развития экономики СССР, продолжили углублять влияние на хозяйство собственных противоречий и создавать разрушавшие изнутри экономику СССР «черные дыры» разбалансировки.

Мультипликативный эффрект ОПК может иметь лишь короткий период действия, в дальнейшем комплекс обязан содержать антикризисные стратегии и страховые мероприятия (даже опытно-экспериментальные виды деятельности) по поиску путей успешной конвертации в гражданское производство. Этап затухания мультипликативных свойств в развитии ОПК по типу ВПК тем масштабнее и короче, чем менее развитие ВПК связано с разрешением диспропорций в рамках проблемных для хозяйства секторов.

Кризисные предпосылки противоречивой динамики ряда сфер экономики СССР, сохранившиеся и актуальные для текущего этапа развития постсоветского хозяйства РФ, нетрудно обнаружить. Например, развитие добывающего сектора, имевшего огромное значение для экономики Советского Союза, как правило, ограничивалось разработкой существующих и вновь открываемых месторождений, т. е. носило экстенсивный характер. Так, за 1940-1985 гг. добыча нефти увеличилась в 19,1 раза, газа - в 200,1, угля - в 4,4 раза [5, с. 163].

Организации сырьевого профиля не были заинтересованы в качественном улучшении положения, их приоритет был обеспечен инвестициями от государства: вложения в топливно-энергетический комплекс (далее - ТЭК) существенно превышали вливания в другие отрасли. В частности, в 1971-1975 гг. капитальные вложения в ТЭК составили 56,8 млрд р. (10,1 \% от всего объема инвестиций в народное хозяйство), в то время как в машиностроительный комплекс 43,1 (7,6), строительный - 31,4 (5,6), химико-лесной - 28,3 (5,0), металлургический 23,7 млрд р. (4,2 \%). В дальнейшем данные диспропорции только усугублялись: в 1981-1985 гг. капитальные вложения в топливно-энергетический комплекс достигли отметки в 108,9 млрд р., что соответствовало уже 12,9 \% от всех инвестиций [6, с. 330].

Многие территории СССР стали практически полностью зависеть от сырьевого сектора, что негативно сказалось на их комплексном развитии, усилило отставание их инфраструктуры. Яркий дисбаланс в экономике СССР наблюдался и с точки зрения соотношения аграрного и городского секторов народного хозяйства. Слабые стимулы к труду и его невысокая производительность постоянно сопутствовали отечественному АПК. Во многом именно отсутствие либо несбалансированность экономических интересов обусловливали отставание Советского Союза по многим качественным индикаторам развития сельского хозяйства. Так, в 1981-1985 гг. производительность труда в данной области составляла уже менее $20 \%$ от показателя США, снизившись в 1971-1980 гг. до 20 \% от цифрры в 20-25 \% в 1966-1970 гг. [7, с. 13].

Снижавшее производительность труда экстенсивное развитие сельского хозяйства отражало не только плановые масштабные кампании по освоению целинных и залежных земель, но и иные структурные перекосы в развитии экономики, связанные с использованием благоприятной внешнеэкономической конъюнктуры на глобальных ресурсных рынках. Взаимодействие с мировым хозяйством в эти годы во многом ограничивалось экспортом сырья. За 1960-1986 гг. вывоз каменного угля увеличился в 2,7 раза, нефтепродуктов - 3,7, сырой нефтти - 7,3, горючего газа - 396,0 [8]. Устойчивая специализация экономики СССР, проявляющаяся в вывозе первичных ресурсов, проявлялась не только в динамике экспорта сырья, но и в месте, которое занимал этот компонент в структуре экспорта.

Структурный кризис советского народного хозяйства, который сопутствовал распаду СССР, характеризовался крупными диспропорциями экспорта, когда с огромным отрывом лидировали топливно-сырьевые товары. Размеры этого элемента экспорта в 1970-х гг. возросли втрое, в 1985 г. он занял более половины всего объема ввоза, в 4 раза превысив экспорт оборудования, машин и транспортных средств. Тогда как в структуре импорта продукция машиностроения, наоборот, заметно опережала остальные наименования, причем на протяжении всего анализируемого периода. Ее доля с 1970 г. превышала треть всего отечественного импорта [9, с. 647], а к 1990 г. ввоз по данной статье составлял уже 44,8 \%, устойчиво приближаясь к отметке в половину всего импорта [10, с. 661].

Преобладающий импорт машин и оборудования был не единственным структурным перекосом, выступающим в качестве характеристики предкризисных проблем советской экономики. В связи с этим стоит также отметить ввоз по статье продовольственных товаров, выросший к 1980 г. до устойчивой величины >1/5 всего импорта. При этом доля таких товаров в экспорте продолжила дальнейшее снижение до мизерного, почти нулевого, уровня, составив к 1985 г. всего 1,5 \%. Наконец, следует обратить внимание на значительный удельный вес продукции народного потребления во ввозимых товарах, указывающий на явную структурную деформацию хозяйства в пользу военно-промышленного комплекса относительно отраслей, изготавливавших гражданские изделия. 
Таким образом, внешнеторговые отношения Советского Союза представляли собой в основном вывоз сырья и ввоз готовой продукции. При этом зависимость народного хозяйства от факторов мировой конъюнктуры из года в год только усугублялась. Данные особенности взаимодействия с другими странами во многом определяют специфику экспортно-импортных операций и сегодняшнего дня, когда сохраняющаяся чрезмерная зависимость экономики РФ от вывоза топливно-сырьевых ресурсов получила за первое десятилетие нового века повторный стимул благодаря благоприятной внешнеэкономической конъюнктуре на мировых рынках топливноэнергетических и иных сырьевых ресурсов.

Высокая степень зависимости от экспорта топливно-сырьевых ресурсов характерна в первую очередь для бюджетной составляющей хозяйства. Проводимый в настоящее время маневр по переносу налоговой базы с экспорта топливных ресурсов на их добычу фрактически не способен повлиять на экспортно-сырьевую ориентацию российского хозяйства. Создавая итоговые изменения в условиях доходности топливно-сырьевых отраслей и в фрормальных источниках бюджетных поступлений, данный налоговый механизм в части структурных пропорций отечественного хозяйства лишь маскирует за изменением формального потока доходов в бюджет экспортно-сырьевую ориентацию аналогично тому, как ранее в годы СССР скрывалась все в той же структуре бюджета доля ВПК.

Так, согласно официальным данным затраты на оборону в 1989 г. формально составляли лишь около 15,6 \% всех расходов бюджета [11], хотя фрактически в 2-3 раза превышали официальную цифру за счет участия в производстве продукции, предназначенной для ВПК, многих отраслей промышленности, включая важнейший машиностроительный комплекс. Аналогично обозначенный налоговый маневр лишь скроет высокий уровень зависимости бюджета от экспорта топливных ресурсов в налоговых поступлениях от добычи, поскольку спрос на нефтедобычу для ее внутреннего потребления жестко связан со сложившейся структурой национального хозяйства РФ.

Не придает устойчивости потенциалу современного отечественного хозяйства и технологический аспект целевых ориентиров в развитии ВПК в качестве источника дальнейшего распространения технологических инноваций. Казалось бы, многие современные направления индустрии 4.0 (например, большие данные, искусственный интеллект, технологии виртуальной реальности и другие направления формируемой ныне новой индустрии) ввиду необходимости освоения и дальнейшего распространения проще и доступнее связывать именно с передовыми сферами ВПК. Формально на это же указывает и прошлый исторический опыт развития комплекса в рамках СССР, где технические нововведения происходили, как правило, в оборонной промышленности либо в связанных с ней видах промышленной деятельности.

На корреляцию в СССР крупных технологических новшеств с определенными сферами хозяйства влияли высокая капиталоемкость инноваций, длительный срок их окупаемости из-за значительных мобилизационных усилий и поддержки со стороны государства, а также потребности дальнейшего распространения новых технологий в рамках высококонцентрированного по капиталу производства. Парадоксальный вывод экономической истории СССР состоит в том, что сфера ВПК дает лишь первичный и непродолжительный импульс техническому прогрессу, в частности и в условиях новой крупной инновационной «кондратьевской» волны (причем обоих типов индустрии - и 3.0, и, как показано далее, 4.0). Дальнейшая конкуренция Советского Союза в области передовых новшеств привела в последующем к затуханию инновационной волны из-за сужения сфер направленности технологий и ухода от передовых тенденций технического прогресса.

Причиной парадокса сужения инновационных сфер и угасания инновационной волны в рамках СССР выступило отсутствие возможностей для широкого перелива крупных новых технологий в область не военно-промышленной направленности, включая и производство товаров народного потребления. Специфика этой проблемы лишь отчасти имеет корни в директивно-плановой системе хозяйствования, исключавшей появление привычных для рыночных хозяйств гибких связей малых инновационных предприятий с крупными концернами. Другой, более важной, причиной, имеющей отношение и к нынешней рыночной экономике РФ, в частности сферам распространения продукции индустрии 4.0, выступает уровень спроса (доходов) потребителей.

Область отечественного потребления из-за низкого уровня доходов не готова к массовому спросу на продукцию сверхвысоких технологий. При этом заинтересованность производителя в резком увеличении собственных доходов, сохраняющаяся со времен приближения к крушению СССР, негативно влияет на сферу производственного потребления. Это касается и организации потребления со стороны владельца фрирмы по использованию новшеств для получения возможности вывода денег в альтернативные теневые схемы оборота. Подобная функциональная связанность инноваций, их «экономическая отягощенность» условиями, задаваемыми принципами функционирования системы хозяйствования, способны привести к повторению указанного парадокса уже для формально рыночных условий технологического развития экономики РФ. 
Например, использование искусственного интеллекта не исключает технологических ошибок, которые можно неправомерно реализовывать в экономической области, в особенности если предпочтение отдается фрирмам-однодневкам. При этом его задействование в потребительской сорере (в частности, в службе такси) пока чрезмерно капиталоемкое: новейшие технологии могут уйти из данного сегмента, если совокупная цена услуг с учетом его использования превысит порог чувствительности доходов массового потребителя.

Функциональную роль плановой системы хозяйствования в торможении первоначальных импульсов внедрения инноваций традиционно связывают с директивной формой планирования в СССР. Однако у данной схемы есть и другая историко-экономическая корреляция с негативным воздействием на инновационный процесс, наблюдаемая с 2014 г. в дирижерском типе стратегического планирования в РФ. Речь, в частности, идет о необходимости разработки системы ограничений деятельности чиновников в тех областях бизнеса, которые не имеют прямого отношения к подконтрольной государственной собственности, но при этом из-за поставленных планированием целевых показателей касаются интересов частного бизнеса. Таким образом, учет подобных функциональных условий в целях успешного развития инновационного потенциала не менее важен, чем его технологические или структурные особенности распространения и влияния на национальное хозяйство РФ.

\section{Ссылки и примечания:}

1. Шваб К. Четвертая промышленная революция : пер. с англ. М., 2019. 209 с.

2. Global Perspectives in Convergence Education [Электронный ресурc] : Workshop Report // National Science Foundation. 2017. Nov. 2-3. 88 р. URL: https://www.nsf.gov/crssprgm/nano/reports/ConvergenceEducation.pdf (дата обращения: 04.06.2019).

3. Широв А.А., Гусев М.С., Фролов И.Э. Макроэкономические эффекты оборонных расходов России: ретроспективный анализ и прогноз // Проблемы прогнозирования. 2018. № 4 (169). С. 3-16.

4. Gemmell N., Kneller R., Sanz I. Does the Composition of Government Expenditure Matter for Long-run GDP Levels? : Victoria University of Wellington Public Finance Working Paper No. 10.2014. 40 p. http://dx.doi.org/10.2139/ssrn.2484917.

5. Народное хозяйство СССР за 70 лет : юбилейный статистический ежегодник. М., 1987. 766 с.

6. Там же. С. 330 .

7. Там же. С. 13.

8. Рассчитано по: Народное хозяйство СССР за 70 лет. С. 641.

9. Там же. С. 647.

10. Народное хозяйство СССР в 1990 г. : статистический ежегодник. М., 1991. 752 с.

11. Рассчитано по: Народное хозяйство СССР в 1990 г. С. 16.

\section{References:}

Gemmell, N, Kneller, R \& Sanz, I 2014, Does the Composition of Government Expenditure Matter for Long-run GDP Levels? Victoria University of Wellington Public Finance Working Paper No. 10. 2014, 40 p., http://dx.doi.org/10.2139/ssrn.2484917.

'Global Perspectives in Convergence Education: Workshop Report' 2017, National Science Foundation, Nov. 2-3, 88 p., $<$ https://www.nsf.gov/crssprgm/nano/reports/ConvergenceEducation.pdf>.

National Economy of the USSR for 70 Years: Anniversary Statistical Yearbook 1987, Moscow, 766 p., (in Russian).

National Economy of the USSR in 1990: Statistical Yearbook 1997, Moscow, 752 p., (in Russian).

Schwab, K 2019, The Fourth Industrial Revolution, Moscow, 209 p., (in Russian).

Shirov, AA, Gusev, MS \& Frolov, IE 2018, 'Macroeconomic Effects of Russian Defense Spending: Retrospective Analysis and Forecast', Problemy prognozirovaniya, no. 4 (169), pp. 3-16, (in Russian). 